\title{
As representações sociais de professores quanto ao ensino de Música mediado por Tecnologias
}

José Magnaldo de Moura Araújo Juciane Araldi Beltrame

Recebido em 04/06/2018

Aprovado em 08/10/2018 
Este trabalho buscou analisar quais as representações sociais de professores ${ }^{1}$ de música sobre ensino de música mediado por tecnologias. Como fonte de dados dessas representações sociais analisamos os formulários de inscrição dos professores inscritos no curso de extensão "Diálogos e conexões sobre educação musical e tecnologias", tendo como base seu perfil e em específico suas perspectivas sobre o que pretendem aprender no curso. A partir da realização desse trabalho tivemos ideia do quanto são diversificadas as representações sociais dos participantes do curso sobre o que é trabalhar com o ensino de música mediado por tecnologias. De modo geral podemos destacar 8 representações sociais divergentes, mas que dialogam entre si formando uma representação social coletiva dos professores de música participantes do referido curso

Palavras-chave: formação de professores; tecnologias; representações sociais.

\section{INTRODUÇÃO}

Os diálogos e conexões com as tecnologias têm se mostrado como uma necessidade nas práticas pedagógicas musicais contemporâneas, sobretudo para somar forças com várias iniciativas que visam promover uma educação mais acessível e democrática. No entanto, muitos professores de música têm enfrentado desafios para atuarem com as tecnologias na sala de aula, justamente devido as representações sociais que eles trazem sobre a própria definição de tecnologias e qual o seu papel na construção de possibilidade de educação musical online e presencial.

Pensando em contribuir para a formação de professores de música que atuam em múltiplos contextos, em maio de 2017 aprovamos um projeto de extensão na Universidade Federal da Paraíba (UFPB) por meio do edital de fomento a extensão, PRAC n 02/2017 do Programa de Bolsas de Extensão - (PROBEX).

\footnotetext{
1 Nesse texto estamos chamando de professores todos os inscritos no curso. Como o perfil de inscritos era aberto, tivemos alunos que cursam licenciatura (portanto professores em formação) e professores da rede pública de ensino.
} 
O projeto tem como título "Educação musical online e mista: estrutura, metodologias e oferta de cursos de extensão de curta duração". Este projeto tem como objetivo oportunizar um espaço laboratório para estudantes de licenciatura em música visando a criação e viabilização de cursos de extensão em música nas modalidades online e/ou mistas para comunidade interna e externa à UFPB.

Dentro das ações do projeto criamos o curso de extensão “Diálogos e conexões sobre educação musical e tecnologias que tem como objetivo capacitar professores envolvidos com música e educação para atuar com ensino e aprendizagem de música mediado por tecnologias digitais, tanto em cursos presenciais quanto virtuais.

O curso busca propor alternativas para que professores da educação básica, professores do ensino superior, professores que atuam em Organizações Não Governamentais (ONGs) e em outros espaços de ensino e aprendizagem de música desenvolvam estratégias de intervenção em suas realidades buscando desenvolver atividades de música mediadas por tecnologias.

Com o advento das novas mídias, as relações de poder e domínio do saber se modificam trazendo a possibilidade de os indivíduos aprenderem por meio do YouTube, do Facebook do Google e acessar milhões de bits de informação sobre determinado tema. O que interfere diretamente nas relações didáticas entre o aluno, o professor e o objeto de aprendizagem (CHAIB, 2015).

Somada a essa emergente realidade a escola e os professores se mostram despreparados para lidar com alunos nativos digitais, tendo em vista que boa parte dos professores acreditam saber menos sobre computadores e internet do que seus alunos (CUERVO, 2012). Por isso a necessidade de pensarmos em um curso de formação continuada para professores de Música, considerando inclusive as especificidades da área.

Partindo dessas discussões, esse trabalho tem como objetivo analisar quais as representações sociais de professores de música sobre ensino de música mediado por tecnologias digitais. Como fonte de dados dessas representações sociais 
iremos analisar os formulários de inscrição dos professores inscritos no curso de extensão, tendo como base seu perfil e em específico suas perspectivas sobre o que pretendem aprender no curso. ${ }^{2}$

\section{O CONCEITO DE TECNOLOGIA}

Nesse trabalho torna-se primordial discutirmos o conceito de tecnologias para termos uma maior clareza sobre esse termo. Nesse sentido Veraszto et. al (2008, p. 78) ao tratar sobre o conceito de tecnologia afirmam que é "[...] um conjunto de saberes inerentes ao desenvolvimento e concepção dos instrumentos (artefatos, sistemas, processos e ambientes) criados pelo homem através da história para satisfazer suas necessidades e requerimentos pessoais e coletivos" ou seja, as tecnologias são meios de facilitar a vida do Homem no mundo.

Desta forma, Sancho (1998, p. 17) complementa entendendo as tecnologias como um "conjunto de conhecimentos que permite a nossa intervenção no mundo ou conjunto de ferramentas físicas ou de instrumentos psíquicos ou simbólicos que nos auxiliam na prática" dando possibilidades e criando formas do Homem se relacionar com as informações, com os outros e com a natureza.

As tecnologias, se associadas ao ensino e aprendizagem, trazem novas possibilidades de intervenção no processo educativo, possibilitando outras perspectivas e orientações de abordagem educacional de como podemos planejar nossas aulas e como pensar na aprendizagem dos nossos alunos ultrapassando os limites das salas de aulas. Portanto, quando tratamos do conceito de tecnologias educacionais estamos pensando em ferramentas intelectuais organizadoras criadas pelos diferentes envolvidos no planejamento, na prática e avaliação do ensino (SANCHO, 1998).

Afunilando um pouco mais essa discussão para o conceito de tecnologias educativo-musicais podemos chegar a um

\footnotetext{
2 O perfil e as perspectivas dos alunos sobre o que desejam aprender no curso nos dão algumas pistas das suas representações sociais sobre o tema. Mas, temos consciência de que é necessária a realização de um estudo mais aprofundado sobre os seus discursos ao longo do curso e consequentemente suas ações que podem dar um maior sentido a análise das suas representações sociais.
} 
consenso de que esse termo se refere a um conjunto de saberes, ferramentas intelectuais e recursos facilitadores criados para satisfazer as necessidades dos diferentes envolvidos no processo de pesquisa, planejamento, avaliação, ensino e aprendizagem de música nos diferentes contextos, nos dando uma perspectiva mais geral do conceito e mostrando toda sua abrangência. Nesse artigo iremos nos deter de modo mais específico as tecnologias digitais, principalmente pela natureza do curso que foi ofertado na modalidade online e semipresencial.

\section{O OLHAR SOCIOLÓGICO PARA ENTENDER AS REPRESENTAÇÕES SOCIAIS SOBRE EDUCAÇÃO MUSICAL MEDIADA POR TECNOLOGIAS}

A teoria das representações sociais nos traz contribuições importantes para refletirmos sobre a educação musical mediada por tecnologias. Uma delas está no modo de como podemos considerar o contexto musical do aluno a partir de suas representações sociais. Ao entendermos as representações sociais dos professores de música participantes do curso estamos propondo um olhar sociológico sobre os saberes e concepções prévias trazidas por eles para sala de aula, sobre os diversos usos das tecnologias e sobre a música. Segundo Duarte e Mazzotti a teoria das representações sociais

é uma forma sociológica, mais do que psicológica, de psicologia social e dá conta das questões relativas às diferentes percepções que sujeitos socialmente configurados constroem de um mesmo assunto, tema, objeto [...] A representação social é definida como um tipo específico de conhecimento que tem por função a elaboração de comportamentos e a comunicação entre indivíduos. É um conhecimento socialmente elaborado e partilhado, com objetivo prático, concorrendo para a construção de uma realidade comum a um conjunto social. (DUARTE; MAZZOTTI, 2006, p. 1285).

Por essa perspectiva podemos de modo mais incisivo refletir sobre a bagagem musical dos professores e propor um ensino de música mais significativo e coerente com a realidade sócio histórica de cada sujeito, contribuindo para 
efetivação de uma educação musical mais contextualizada e democrática.

Além disso, um olhar mais atento para as representações sociais dos sujeitos que participam do curso poderá nos proporcionar uma percepção mais clara sobre como eles enxergam as Tecnologias de Informação e Comunicação (TICS) e como elas interferem diretamente nas concepções deles sobre o que é aprender música e o que habilita alguém a ensinar música mediado por tecnologias, etc. Tais aspectos podem nos ajudar a repensar nossas práticas pedagógicas e refletir sobre as diferentes representações sociais dos sujeitos que buscam aprender música em múltiplos contextos. Os autores Duarte e Mazzotti chamam a atenção para a necessidade de olhar as "concepções prévias" dos alunos. Nas suas palavras:

A abordagem das representações sociais investiga e apreende os processos e produtos do senso comum, ou seja, dos sentidos comuns aos sujeitos pertencentes a um determinado grupo. Logo, pode ser de grande utilidade na determinação das "concepções prévias" apresentadas pelos alunos e professores na constituição de suas teorias. (DUARTE; MAZZOTTI, 2006, p. 1290).

Desse modo, um dos motivos que nos levou a estudar as representações sociais dos participantes do curso "diálogos e conexões sobre música e tecnologia" está ligado ao fato de que as concepções prévias que eles já traziam para o curso sobre educação musical mediada por tecnologias seriam fator sine qua non para construção do nosso curso. Assim, as representações sociais deles seriam o nosso ponto de partida para construção didática do curso. A perspectiva de considerar o universo dos sujeitos que buscam cursos, e até mesmo os alunos que estão nas salas de aulas em ambientes formais, perpassa a produção de conhecimento da área de educação e de educação musical. Conforme apontado por Duarte e Mazzotti:

O conhecimento adquirido por meio de livros, informações impressas, na sala de aula e monitorado por professores é desafiado pelo conhecimento obtido por crianças e adultos, de forma independente, fora do 
contexto do ensino formal, por meio, por exemplo, da Wikipédia, do Google e do Facebook. A nova tecnologia não cria, por si só, novas representações do mundo, nem novos conhecimentos, mas contribui substancialmente para a difusão das concepções das pessoas e das representações do mundo, de maneira rápida e global. O desafio para os professores é compreender que tipo de representações as pessoas trazem com elas para a escola. (DUARTE; MAZZOTTI, 2006, p. 1290).

Nessa perspectiva, buscamos compreender as representações sociais dos sujeitos participantes do curso porque tínhamos consciência de que nosso trabalho não seria apenas de repassar o conhecimento, mas de dialogar com as representações sociais trazidas pelos sujeitos, evitando uma abordagem linear e conteudista focada na ideia de que os participantes precisavam apenas aprenderem a manusear ferramentas tecnológicas.

Precisávamos ajudá-los a transcender a ideia utilitária de tecnologia como ferramenta e instrui-los a mediar o ensino de música por tecnologias nos múltiplos contextos de atuação profissional, aproveitando o que eles já conheciam e criando situações de diálogos com outros colegas do curso para que pudessem estabelecer trocas de saberes sobre o tema.

A seguir iremos apresentar uma breve reflexão sobre as gerações de nativos digitais e imigrantes digitais, para a partir disso conduzirmos uma discussão mais aprofundada sobre como as diversas gerações de sujeitos participantes do curso representam o tema educação musical mediada por tecnologias. Para isso iremos realizar uma análise de conteúdo dos formulários de inscrição dos sujeitos participantes do curso, destacando alguns comentários que demonstram divergências na representação social sobre educação musical mediada por tecnologias. Todos os comentários foram feitos pelos professores quando fizeram a inscrição no curso e responderam a seguinte questão: "o que você espera aprender neste curso sobre o uso de tecnologias na educação musical? Fale sobre isso." Por questões éticas iremos identificar os sujeitos como professor seguido do número da sua inscrição no curso de modo a não revelar suas identidades. 


\section{DIÁLOGOS ENTRE GERAÇÕES E REPRE- SENTAÇÕES SOCIAIS SOBRE EDUCAÇÃO MUSICAL MEDIADA POR TECNOLOGIAS}

Ao iniciarmos uma pesquisa sobre o conceito de tecnologias chegamos em um termo que é bastante utilizado na literatura que é "novas tecnologias". Foi a partir disso que nos questionamos: será que as tecnologias são "novas" para todos? Nessa perspectiva, percebemos que cada geração tem uma representação diferente sobre o que são tecnologias e como elas devem ser usadas no cotidiano.

Por isso, Gohn (2010, p. 13) afirma que "pesquisar sobre tecnologia é como perseguir a própria sombra: quando se chega no objeto intencionado o objeto de interesse já está mais à frente" demostrando o quanto o crescimento das tecnologias são exponenciais e ultrapassam as gerações sendo representadas socialmente de diversas formas.

Desse modo, quando tratamos sobre esse tema uma das questões que sempre vem à mente é: devemos abraçar as tecnologias e se adaptar a elas ou devemos firmar resistência para mantermos os nossos processos tradicionais de pensar e fazer as coisas? Esse tem sido um dilema presente nas discussões e práticas acerca do papel das tecnologias na educação, principalmente quando tratamos sobre o ensino e aprendizagem de Música. Como professores, essa questão pode ser pensada da seguinte forma: devemos sempre abraçar e sempre acompanhar esse desenvolvimento exponencial com o intuito de propor uma educação musical contextualizada e articulada com a dinâmica cultural de transformação do mundo ou devemos firmar uma resistência a esse processo acelerado de desenvolvimento firmando nossas convicções em propor uma educação musical pautada em princípios e valores estanques que se dizem a essência do fazer e do saber musical?

Esse é um dilema que não está resolvido e nem pretendemos resolver. Mas, precisamos entender essa complexidade inerente ao tema educação musical mediada por tecnologias digitais pois de fato são questões emergentes na nossa prática pedagógica musical contemporânea. Desse modo, se pensarmos o desenvolvimento tecnológico como um processo de conflitos 
e lutas internas entre o que é inovador e o que é tradicional, veremos que em todas as sociedades esse processo foi vivido de maneira bastante similar.

Por exemplo, se fizermos uma analogia a adaptação em que as pessoas tiveram que fazer ao se depararem com a necessidade de utilizarem livros ao invés de pergaminhos, veremos que o processo de adaptação para aqueles que já estavam habituados a utilizar o pergaminho como principal forma de registro e apreensão do conhecimento não foi fácil. Muitos tiveram dificuldade de modificar esse modo de se relacionar com a leitura pelo fato de já possuírem uma representação social sobre como se deve ler, como se pode aprender e registrar o conhecimento seguindo uma lógica já estabelecida, etc.

Mas, ao mesmo tempo em que existiram pessoas que resistiram a essas mudanças e/ou tiveram dificuldades de se adaptar a ela, também existiram outras que já nasceram na era dos livros e que outra forma de se relacionar com a leitura causa um certo estranhamento e divergência daquilo que para ela é uma representação social fiel de como devemos ler, aprender e registrar o conhecimento. E esses conflitos se perpetuam com o uso cada vez mais constante dos e-books nos pequenos aparelhos leitores de livros digitais em contraposição ao abandono da compra de livros físicos ${ }^{3}$.

Outros exemplos podem ser citados com o modo de registrar as músicas que antes só era possível pela partitura agora já podemos realizar gravações em diversos formatos e até transcrever essas gravações com ajuda de softwares que reconhecem as notas e transformam em partitura. Esses são alguns exemplos de processos de mudanças que rompem com estruturas e representações sociais que são difíceis de serem compreendidas e aceitas de modo imediato pela sociedade.

É nessa perspectiva que sempre temos pessoas que firmam resistência a algumas mudanças tecnológicas e outras que aderem facilmente sem nenhum conflito interno e/ou externo sobre como proceder com o uso dessa nova forma de se relacionar com as coisas e/ou com as pessoas. Com a era digital,

\footnotetext{
${ }^{3}$ As redes sociais também são exemplos de tecnologias disruptivas que ainda enfrentam certa resistência por alguns indivíduos ao mesmo tempo em que existem sujeitos que aderiram facilmente a essa nova forma de se relacionar com as pessoas.
} 
Marc Prensky (2001) distinguiu esses dois perfis de pessoas como nativos digitais e imigrantes digitais.

Os Imigrantes digitais são aquelas pessoas que precisam se adaptar as novas ferramentas ou formas de se fazer as coisas; são pessoas, por exemplo, que precisam aprender a utilizar Tecnologias da Informação e Comunicação (TICs) em um processo de inclusão digital, pois não nasceram em meio a tantas TICS.

Esses sujeitos, algumas vezes, se sentem frustrados diante do aprendizado de diferentes tecnologias e possuem uma certa resistência a inovação das ferramentas e formas de fazer as coisas. Em alguns casos, muitos imigrantes digitais desenvolvem uma fobia as tecnologias, tornando-se tecnófobos, que são indivíduos que se recusam a ultrapassar os limites da sua zona de conforto, restringindo sua aprendizagem apenas aquilo que é essencial para sua sobrevivência (GOHN, 2007).

Já os nativos digitais são pessoas que possuem uma maior desenvoltura e capacidade no uso de tecnologias digitais. Independentemente da idade são sujeitos que aderem de forma rápida e transparente a novas tecnologias com naturalidade e fluência sem demonstrar muitas dificuldades no uso de ferramentas e novas formas de pensar os processos. Como já nasceram imersos no rápido progresso das novas TICs, tiveram seu desenvolvimento afetado por elas demonstrando, algumas vezes, dificuldades de lidar com o grande número de informações principalmente na hora de organizá-las. Outra característica de alguns desses sujeitos é a tendência de ser multitarefas, que acaba por desenvolver uma certa dificuldade em focar e manter a atenção na realização de uma única tarefa de cada vez. Nesse sentido, constata-se uma outra forma de lidar com o conhecimento, o que Lévy (2010) chama de "nova relação com o saber" e assim, existem outras formas de aprender e consequentemente outras formas de ensinar.

Na sociedade contemporânea a presença desses dois perfis de sujeitos é comum. Com o aumento da expectativa de vida do ser humano cada vez mais temos pessoas de diferentes gerações ocupando espaços sociais em empresas, escolas, organizações não governamentais, dentre outros. Sendo assim, as gerações estão cada vez mais tendo que trabalhar juntas o que demonstra a necessidade de pensarmos em estratégias 
que ajudem essas gerações a conviverem, principalmente nos espaços de ensino e aprendizagem de Música.

\section{AS REPRESENTAÇÕES SOCIAIS DOS ALUNOS DO CURSO DIÁLOGOS E CONEXÕES SOBRE MÚSICA E TECNOLOGIAS}

Para análise das representações sociais dos professores participantes do curso diálogos e conexões sobre música e tecnologias, iremos partir das expectativas deles para participar do curso. O foco nesse texto é na fase inicial, o período de inscrições, mas em trabalhos posteriores pretendemos focar nas representações sociais que eles construíram após o curso, como vistas a analisar se houve mudanças de perspectivas sobre o que é trabalhar com o ensino de música mediado por tecnologias.

Os primeiros comentários que destacamos é do professor 02 e do professor 10 que possuem uma representação social sobre aulas de música mediada por tecnologias relacionada a uma visão ferramental da tecnologia como meio de realizar alguma tarefa. A seguir seus relatos:

Espero adquirir conhecimento e habilidade para manusear os meios tecnológicos nas aulas de música para a educação infantil (PROFESSOR 10)

Dou aulas de: ukulele, violão, gaita e percussão. Tenho um Instituto de Música, e invisto na educação a distância, gravo aulas para o Youtube, e umas pequenas chamadas no Instagram e postagens convidativas no Facebook para as tradicionais aulas presenciais, todos agregados e sincronizados. Procuro sempre reforçar os conteúdos com diversos recursos aplicáveis, com o intuito de facilitar e fixar os exercícios, para uma excelente aprendizagem, espero que esse curso venha somar em minha vida (PROFESSOR 02).

Para esses professores, utilizar redes sociais e manusear equipamentos tecnológicos são uma forma de trabalhar com o ensino de música mediado por tecnologias, demonstrando que apenas o ato de se relacionar com as tecnologias já representa para eles uma forma de mediação do ensino. No 
entanto, precisamos compreender que trabalhar com o ensino de música mediado por tecnologias vai muito além de apenas manusear equipamento. Se faz também necessário repensar a metodologia de como utilizamos esses equipamentos de modo a mediar o ensino por eles e não apenas adaptar o analógico ao digital como representa a fala do professor 02 .

Outra representação social que encontramos foi a da tecnologia como ferramenta de enriquecimento das aulas de Música. Para o professor 01 a sua perspectiva no curso é "Conhecer novas ferramentas que possam enriquecer minha metodologia em sala de aula". (PROFESSOR 01). Essa representação social demonstra que para alguns sujeitos o ato de utilizar uma nova ferramenta tecnológica, um software, um jogo digital é fator de enriquecimento das aulas. No entanto, é preciso refletirmos se o "uso pelo o uso" é suficiente para enriquecer o processo de ensino e aprendizagem. Afinal, se mudamos as ferramentas também precisamos modificar 0 processo de ensino e aprendizagem e refletir sobre o 'como' mediar o ensino por meio das tecnologias e não apenas manusear elas em sala de aula como, por exemplo, transferir o ato de escrever no quadro para o ato de escrever no editor de texto e projetar para os alunos. Como ressalta Cernev:

[...] a motivação dos alunos para aulas de música utilizando as tecnologias digitais pode ocorrer satisfatoriamente se o professor se valer de estratégias motivacionais autônomas e buscar o compartilhamento de informações de forma colaborativa com seus alunos em sala de aula, o que suporta o senso de autonomia, competência e pertencimento dos estudantes. (CERNEV, 2015, p. 188)

Outra representação social bastante recorrente é a da aula de editar músicas utilizando softwares de edição de partitura no computador. Para o Professor 05, essa é a representação social construída durante o seu curso de graduação.

Desde o início da graduação muito dos professores pediam para que nos acostumássemos a utilizar tais tecnologias. Sendo assim, mesmo não havendo nenhuma disciplina específica que trabalhasse com, por exemplo: Finale, MuseScore e Sibelius, fomos tendo contato mesmo que superficial sobre esses editores e reprodutores de partitura. [...] Vejo então que esse curso pode favorecer 
não somente à formação acadêmica musical, quanto reflexionar ainda mais sobre os programas disponíveis para o ensino (PROFESSOR 05).

Talvez, essa representação social do professor 05 esteja ligada a disciplinas como computação musical, música e tecnologia e outras diversas variações desse mesmo nome que, muitas vezes, se fecham em apenas ensinar os alunos a manusear softwares de edição de partitura não mostrando outras possibilidades de como o professor pode mediar o uso de tecnologia no seu fazer profissional que envolve pesquisar, planejar, ministrar aulas e avaliar. Trata-se de buscar compreender o papel das tecnologias na vida das pessoas, e principalmente dos alunos e suas diferentes formas de se relacionar com a música e tecnologia, como por exemplo as escutas compartilhadas (BELTRAME, 2016), a escuta portátil (RAMOS, 2012), a relação de jovens com as mídias (SOUZA e FREITAS, 2014), engajamento entre pessoas, músicas e mídias (TOBIAS, 2013; 2015).

Assim, é possível pensar em atividades mediadas pelas tecnologias, demostrando uma necessidade de repensarmos como esses conhecimentos e saberes podem favorecer a formação de professores de Música para atuar com ensino de música em diálogo com as tecnologias e não apenas transcrever, criar arranjos e músicas manuseando editores de partituras se limitando a aprender apenas a utilizar o recurso, ou seja "apertar botão".

Outro comentário do professor 05 diz respeito a representação social da tecnologia como instrumento de diálogo e maior interação com os nativos digitais nas aulas de música. Ele comenta: "Trabalho como professor de Música desde os 15 anos e, hoje aos 21 percebo que os alunos ao qual tenho contato são mais dinâmicos por causa do acesso com as novas tecnologias" (PROFESSOR 05). Esse comentário demonstra um reconhecimento de que a linguagem tecnológica é algo em que seus alunos já dominam e que ele se preocupa em acompanhar e entender como mediar o ensino de música pelas tecnologias, favorecendo o diálogo e a compressão dos alunos dentro do processo de ensino e aprendizagem. Aqui podemos fazer uma ressalva que o "acompanhar" é no sentido de acolher, trazer para dentro da sala, e não necessariamente querer saber 
sobre todos os recursos para ensinar os alunos. Esse é um dos fatores chave que ajudam a entender o papel de mediador que o professor assume, logo que, em muitos dos casos, os alunos já dominam os recursos tecnológicos, e o seu papel é de fato, provocar esses alunos a utilizarem esse conhecimento para construção de novos conhecimentos, no nosso caso, musicais.

Outra representação social que poucos professores tiveram, diz respeito a tecnologia como meio de expansão das ideias e possibilidades nas aulas de música. Para o professor 12 e 0 professor 08 o maior desejo deles diz respeito à "Como inserir e criar ideias na educação básica através da tecnologia" (professor 12); "como ampliar minhas possibilidades de trabalho na área da música, usando a tecnologia digital" (PROFESSOR 08). Esses comentários dos professores demonstram uma representação social das tecnologias como um meio de criar possibilidades para o ensino e não apenas modificar os processos. Com o advento das mídias as possibilidades de aprender música se expandiram bastante. No entanto, cabe ao professor refletir e solucionar problemas de forma criativa com ajuda das tecnologias nas aulas de Música de modo a trazer novas possibilidades para 0 ensino e aprendizagem

Nessa perspectiva, criar possibilidades e ideias também diz respeito a representação social das tecnologias como meio de inovar nas aulas de música. Para o professor 24 essa é a representação social de como ele pode trabalhar com o ensino de Música mediado por tecnologias. Por isso ele buscou o curso com um único objetivo de "Aperfeiçoamento de habilidades educacionais com o objetivo de inovar através do uso consciente dessas ferramentas, atentando às perspectivas de um novo contexto sociocultural em um novo 'fazer musical"' (PROFESSOR 24). Somado a esse comentário também temos a representação das tecnologias como uma nova possibilidade metodológica de trabalhar com ensino de música na escola para o professor 28 e professor 32.

Novas metodologias de como abordar tecnologias na sala de aula, sendo que grande parte das escolas da educação básica do município em que eu atuo não disponibilizam de computadores, e quando se tem não há internet. Assim pretendo saber também como aplicar tecnologias sem especificamente utilizar internet (Professor 28) 
Espero expandir meus conhecimentos sobre as tecnologias digitais à minha disposição e aprender a como utilizá-las na prática de sala de aula, de forma a contribuir da melhor maneira possível para o aprendizado e crescimento dos alunos com quem tenho contato (Professor 32)

Oscomentáriosdosprofessoresatentampararepresentação social de que as tecnologias são meios de criação de novas poéticas musicais e inovação no ensino de música, expandido ainda mais as concepções sobre a aula de música mediada por tecnologias. Demonstram assim que as perspectivas da aula de música também se modificam com a mudança das concepções e que conforme as tecnologias se transformam, cada vez mais depressa estamos tendo que repensar nosso fazer musical e nossas formas de ensinar e aprender música. Tal representação se articula com as discussões sobre cultura digital no ensino e aprendizagem musical (TOBIAS, 2015; BELTRAME, 2016) quando ressaltam as possibilidades de engajamento entre pessoas, músicas e mídias e como isso muda as formas de ouvir, tocar, aprender e ensinar música.

Por fim, destacamos a representação social das tecnologias como meio de inclusão que para o professor 48 "Fazer uso da tecnologia na educação é uma utilidade inadiável, pois daremos um aspecto mais dinâmico e interativo tendo em vista, as necessidades individuais de cada aluno em prol de um melhor aprendizado" (Professor 48). Essa representação social corrobora também com a preocupação de muitos professores do curso que estão buscando criar jogos musicais e metodologias de como incluir pessoas com deficiência auditiva e pessoas com deficiência visual, demostrando que as tecnologias assistivas também são possibilidades de trabalhar com o ensino de música mediado por tecnologias para incluir o outro e dialogar com a diversidade (LOURO, 2005).

\section{CONSIDERAÇÕES FINAIS}

Esse trabalho buscou analisar as representações sociais de professores de música sobre ensino de música mediado por tecnologias. Como fonte de dados dessas representações sociais analisamos os formulários de inscrição dos professores matriculados no curso de extensão “Diálogos e conexões sobre 
educação musical e tecnologias", tendo como base seu perfil e em específico suas perspectivas sobre o que pretendem aprender no curso.

A partir da realização desse trabalho tivemos ideia de quanto são diversificadas as representações sociais dos participantes do curso sobre o que é trabalhar com o ensino de música mediado por tecnologias. Além disso, percebemos um grande conflito conceitual sobre ferramentas tecnológicas, tecnologias digitais e tecnologias sociais, demonstrando que ainda não existe um senso comum sobre o que significa cada termo, mas que em outros estudos poderemos aprofundar essa discussão.

De modo geral podemos destacar 8 representações sociais divergentes, mas que dialogam entre si formando uma representação social coletiva dos professores de música, participantes do curso, sobre o ensino de música mediado por tecnologias. A saber: 1- representação social sobre aulas de música mediada por tecnologias relacionada a uma visão ferramental da tecnologia; 2- representação social da tecnologia como ferramenta de enriquecimento das aulas de Música; 3- representação social da aula de música mediada por tecnologia como aula de editar músicas utilizando softwares de edição de partitura no computador; 4- representação social da tecnologia como instrumento de diálogo e maior interação com os nativos digitais nas aulas de música; 5- representação social da tecnologia como meio de expansão das ideias e possibilidades nas aulas de música; 6- representação social das tecnologias como meio de inovar nas aulas de música; 7- representação social das tecnologias como uma nova possibilidade metodológica de trabalhar com ensino de música na escola; e 8- Representação social das tecnologias como meio de inclusão.

Esse trabalho é apenas um recorte dos comentários dos professores participantes do curso no momento de inscrição. Outros trabalhos poderão se aprofundar um pouco mais sobre as representações sociais dos professores analisando comentários e falas desses professores durante o curso e como essas representações se modificaram ou não depois do curso.

Esperamos, com esse trabalho, contribuir para uma 
reflexão maior sobre como os sujeitos representam o ensino e aprendizagem de música mediado por tecnologias antes de terem um contato com essas possibilidades nos espaços e instituições de ensino e aprendizagem musical. Outros trabalhos poderão focar como as diversas gerações se relacionam com aprendizagem de música mediado por tecnologias e como elas representam socialmente essas vivências. 


\section{REFERÊNCIAS}

BELTRAME, Juciane Araldi. Educação musical emergente na cultura digital e participativa: uma análise das práticas de produtores musicais. 2016. Tese (programa de pós-graduação em música) - centro de letras e Artes - Universidade Federal do Estado do Rio de Janeiro, Rio de Janeiro, 2016.

CERNEV, Francine Kemmer. Aprendizagem musical colaborativa mediada pelas tecnologias digitais: motivação dos alunos e estratégias de aprendizagem. 2015. Tese (doutorado em Música) - Instituto de Artes, Universidade Federal do Rio Grande do Sul, Porto Alegre, 2015.

CHAIB, M.; CHAIB, M. Social representations, subjectivity and learning. Cadernos de Pesquisa, v. 45, n. 156, p. 358-372, 2015.

CUERVO, Luciana. Educação musical e a ideia de arquiteturas pedagógicas: práticas na formação de professores da geração "nativos digitais". Revista da $A B E M$, v. 20, n. 29, 2012. Disponível em: <http://abemeducacaomusical.com. $\mathrm{br} /$ revistas/revistaabem/index.php/revistaabem/articl e/ view/91>. Acesso em: 26 maio. 2018.

DUARTE, M. De A.; MAZZOTTI, T. B. Representações sociais da música: aliadas ou limites do desenvolvimento das práticas pedagógicas em música? Educação e Sociedade, v. 27, n. 97, p. 1283-1295, 2006.

GOHN, Daniel Marcondes. Tecnofobia na música e na educação: origens e justificativas. OPUS, v. 13, n. 2, p. 161174, 2007.

. Educação musical à distância: propostas para ensino e aprendizagem de percussão. 2010. Tese (Doutorado em Interfaces Sociais da Comunicação) - Escola de Comunicações e Artes, Universidade de São Paulo, São Paulo, 2010.

LEVY, Pierre. Cibercultura. São Paulo: Editora 34, 2010. 
LOURO, Viviane. Educação Musical e o Aluno com Deficiência: discutindo a prática e propondo adaptações pedagógicas, 2005. Disponível em: <https://musicaeinclusao.wordpress. com/2013/06/06/louro-viviane-educacao-musical-e-oaluno-com-deficiencia-discutindo-a-pratica-e-propondoadaptacoes-pedagogicas/>. Acesso em: 5 out. 2018.

PRENSKY, Marc. Nativos digitais, imigrantes digitais. Tradução de Roberta de Moraes Jesus de Souza, [s. I.], v. 9, n. 5, 2001.

RAMOS, Sílvia Nunes. Escuta portátil e aprendizagem musical: um estudo com jovens sobre a audição musical mediada pelos dispositivos portáteis. 2012. Tese (Doutorado em Música) 271 Programa de Pós-Graduação em Música, Universidade do Federal do Rio Grande do Sul, Porto Alegre.

SOUZA, Jusamara; FREITAS, Maria de Fatima Quintal de. Práticas musicais de jovens e vida cotidiana: socialização e identidades em movimento, Curitiba, Música em perspectiva, v. 7, n. 1, p. 57-80, 2014.

SANCHO, Juana Maria. Por Uma tecnologia educacional. Porto Alegre, Artmed, 1998.

TOBIAS, Evan. Inter/trans/cross/new media(ting): Navigating an emerging landscape of digital media for music education. In: RANDLES, C. (Ed.), Music education: navigating the future. New York: Routledge, 2015. p. 91-121

Toward Convergence: Adapting Music Education to Contemporary Society and Participatory Culture. Music Educators Journal, v. 99, n. 4, p. 29-36, 2013.

VERASZTO, Estéfano Vizconde et al. Tecnologia: buscando uma definição para o conceito. Revista Prisma.com, n.7, p.60-85, 2008. 